\title{
Digitale en fysieke zorg: op zoek naar evenwicht
}

\author{
Frank van Wijck
}

Published online: 9 augustus 2021

(C) Bohn Stafleu van Loghum is een imprint van Springer Media B.V., onderdeel van Springer Nature 2021

\begin{abstract}
Samenvatting Toepassing van zorgtechnologie kan van meerwaarde zijn voor zorgprofessional én patiënt. De ontwikkeling hiervan is in Nederland traag op gang gekomen, maar heeft door de coronacrisis - noodgedwongen - een forse impuls gekregen, omdat fysiek zorgcontact in die periode tot een minimum moest worden beperkt. Hoogleraar 'Succesvolle technologische innovaties in de zorg' Eveline Wouters (Tranzo, Tilburg University) doet onderzoek naar technologische en sociale innovaties ter ondersteuning van mensen met chronische gezondheidsproblemen. De versnelde en versterkte toepassing van digitale zorg door de coronacrisis zal er niet toe leiden dat alle zorg digitaal wordt, stelt zij. Maar zorgtechnologie zal wel een vaste plaats blijven houden in het werk van alle (para)medische disciplines, ook podotherapeuten.
\end{abstract}

Trefwoorden zorginnovatie $\cdot$ technologie $\cdot$ digitale zorg $\cdot$ chronisch gezondheidsprobleem

Zorgtechnologie doet een belofte: professionals zouden er meer ruimte door krijgen voor het werk waarvoor ze zijn opgeleid en de patiënt meer eigen regie. Wordt die belofte waargemaakt? Hoewel de coronapandemie noodgedwongen een forse impuls heeft gegeven aan de toepassing van zorgtechnologie, zal beslist niet álle zorg digitaal worden, stelt hoogleraar Eveline Wouters. Maar wel zal zorgtechnologie voor alle (para)medische zorgprofessionals een blijvende rol gaan spelen, ook voor podotherapeuten.

Lector 'Health Innovations \& Technology' aan de Fontys Paramedische Hogeschool en bijzonder hoogleraar 'Succesvolle technologische innovaties in de zorg' aan Tilburg University, dat is een interessante combinatie

F. van Wijck ( $(-)$

Eva Tekstproducties, Amsterdam, Nederland frank@evatekst.nl (zie het kader 'Prof. dr. Eveline Wouters'). Zelf vertelt Eveline Wouters (fig. 1) hierover: "Als hoogleraar richt ik mij op hetzelfde onderzoek waarmee ik aan de hogeschool ook al bezig was: technologische en sociale innovaties ter ondersteuning van mensen met chronische gezondheidsproblemen. Het interessante van de combinatie tussen universiteit en hogeschool is de kruisbestuiving in kennisontwikkeling. De universiteit is het wetenschappelijk kennisinstituut en de hogeschool slaat de brug naar de praktijk."

Zorgtechnologie biedt interessante mogelijkheden, is de stelling van Wouters. "Denk bijvoorbeeld aan het thuis monitoren van vitale waarden van de patiënt, waarbij de behandelaar op afstand de patiëntdata kan inzien, of aan online overleg tussen arts en patiënt. Beide betekenen dat de patiënt veel minder vaak fysiek contact met de behandelaar nodig heeft, maar ook dat de patiënt meer eigen regie kan ervaren. We onderzoeken hoe de zorg door technologie verandert en wat er vanuit het menselijk perspectief nodig is om succesvol van die technologie gebruik van te maken, zowel voor de patiënt, de professional als de organisatie."

\section{Relevante vragen}

Het gaat niet snel met die toepassing van zorgtechnologie, erkent Wouters. "Er zitten best veel haken en ogen aan, financieel en juridisch bijvoorbeeld, maar ook op het gebied van veranderende rollen. Het is niet zozeer de technologie op zich die de ontwikkeling tegenhoudt, maar vooral wat het betekent om er gebruik van te maken. Wat is ieders rol bijvoorbeeld? Voor de patiënt betekent de eigen regie die de technologie met zich meebrengt, het nemen van verantwoordelijkheid. Voor de zorgprofessional betekent de technologie juist verantwoordelijkheid uit handen durven geven." 


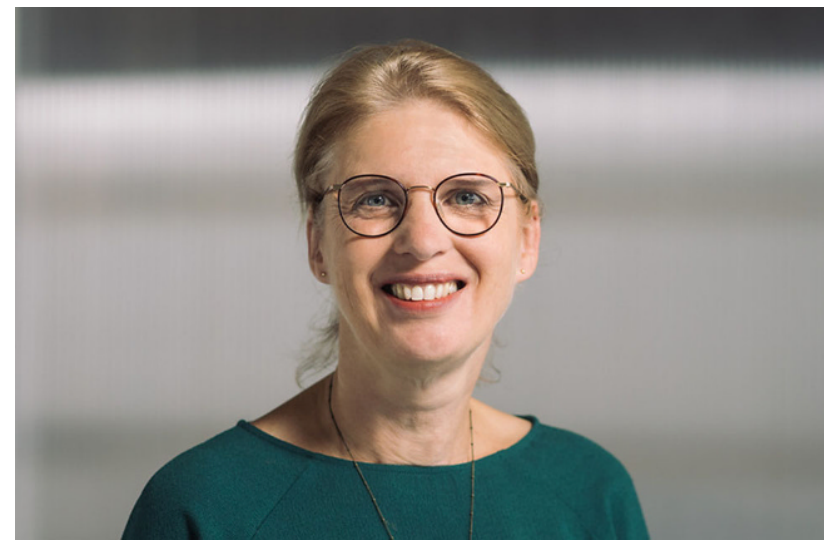

Figuur 1 Prof. dr. Eveline Wouters

Een vraag die niet onbeantwoord mag blijven, is of iedereen wel volwaardig kan omgaan met die digitalisering. Wouters: "Het vereist een zekere digitale vaardigheid om vitale functies te kunnen monitoren en te kunnen inlezen in de computer bijvoorbeeld. Daarmee zul je rekening moeten houden. Zeker als digitale zorg de standaard wordt, is het de vraag of iedereen nog de zorg krijgt die nodig is. Over die vraag wordt nu in het debat over technologische innovatie in de zorg vrij polariserend gedacht. Precies de reden waarom wij er nu onderzoek naar doen, want het is inderdaad goed denkbaar dat de mensen die de zorg het hardst nodig hebben door digitalisering van het zorgaanbod minder goede zorg krijgen. De mensen met beperkte digitale vaardigheden behoren immers vaak tot dezelfde groep als de mensen met beperkte gezondheidsvaardigheden, en als gevolg van dat laatste, de grootste zorgvraag. Op zich is dat geen reden om niet bezig te zijn met digitalisering in de zorg, maar daarbij moet dan met dit aspect wel goed rekening worden gehouden."

\section{Veranderende relaties}

Een ander belangrijk aspect waarnaar bij technologische innovatie in de zorg serieus moet worden gekeken, is samenwerking. Wouters legt uit: "Zorgtechnologie verandert de relatie tussen zorgprofessionals onderling. $\mathrm{Nu}$ zijn de medische en paramedische disciplines veelal nog gescheiden. Maar als je gezamenlijk een patiënt met een beroerte of met kanker gaat behandelen, verandert dat. Je ziet dit ook in de intramurale dementiezorg. Verblijft een oudere met dementie op een psychogeriatrische afdeling van een verpleeghuis, dan is dat een afgebakende setting met een beperkt aantal betrokken zorgprofessionals die volledige controle hebben. Als zo iemand door zorgtechnologie meer bewegingsvrijheid krijgt, vervalt die controle en moet de verantwoordelijkheid gedeeld worden met andere professionals. Dat vraagt om durf en vertrouwen, doordat alle betrokkenen nu ineens veiligheid en vrijheid tegen elkaar af moeten gaan wegen."
Prof.dr. Eveline Wouters

Bijzonder hoogleraar 'Succesvolle technologische innovaties in de zorg' bij Tranzo, Tilburg University en lector Health innovations and technology aan Fontys Paramedische Hogeschool. Haar onderzoek richt zich op acceptatie en implementatie van medische technologie in de gezondheidszorg, in het bijzonder bij mensen met chronische aandoeningen. Andere onderzoeksthema's waarmee zij zich bezighoudt zijn de ontwikkeling van nieuwe technologische toepassingen op het gebied van artificial intelligence en de toegankelijkheid van technologie.

\section{De impuls van corona}

De coronapandemie heeft - noodgedwongen - een enorme impuls gegeven aan digitalisering van de zorg. "Het is een enorme aanjager geweest," zegt Wouters, "mensen zijn veel meer online gaan werken. Ook paramedici, die enige tijd geen patiënten in de praktijk mochten ontvangen - en sommige patiënten durfden niet in de praktijk te komen - hebben zich afgevraagd welke zorg zij nog konden blijven leveren. Al was het maar bellen om in ieder geval het contact te onderhouden en vragen te beantwoorden."

Heeft de pandemie dan zowel de mogelijkheden als de beperkingen van digitalisering in de zorg blootgelegd? "Zeker," antwoord Wouters, "je weet daardoor ook meteen wat je mist en daaruit kunnen we afleiden dat de toekomst van de zorg zich niet volledig online zal afspelen. Wat dat betreft fungeerde de pandemie ook als trigger voor het inzicht dat digitalisering niet altíjd de goede oplossing is. Omgekeerd ben ik er wel van overtuigd dat ook zonder die pandemie de zorg steeds meer digitaal zou zijn geworden. We hadden al apps en andere oplossingen waarmee controles in het ziekenhuis konden worden vervangen door zorg thuis en ook de financiële barrière voor digitale consulten was al deels geslecht."

Er zal vanzelf een nieuw evenwicht ontstaan, verwacht Wouters. "Daarbij kun je je afvragen of de verandering op alle punten even groot zal zijn. Nog steeds gebeuren dingen offline die best online kunnen, maar vaak willen patiënten nog gewoon naar de arts. Een lichamelijk onderzoek vraagt altijd om fysieke aanwezigheid. Toch, als je een chronische ziekte hebt, kan ik me heel goed voorstellen dat je niet voor iedere controle naar de huisarts of het ziekenhuis wilt en dus digitaal contact als een heel welkom alternatief ziet." 


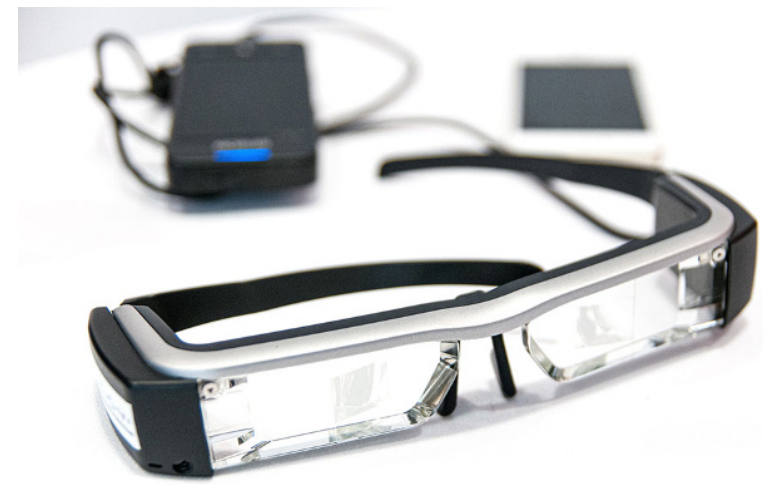

Figuur 2 Google was een van de eerste bedrijven die Smart Glasses op de markt bracht. Inmiddels zijn er vele andere merken ontwikkeld. Deze worden vooral bedrijfsmatig ingezet en in mindere mate door de individuele consument

\section{Algoritmen en mensenwerk}

Technologische innovatie gaat verder dan alleen artspatiëntcontact en zorg op afstand. Die heeft ook betrekking op diagnostiek en behandeling. "In hoeverre robotica voor chirurgische behandeling meerwaarde heeft, weet ik niet," zegt Wouters, "daar heb ik geen zicht op. Maar diagnostiek op basis van algoritmen is zeker haalbaar; het gebeurt al. De radiolaborant zal op basis daarvan bijvoorbeeld veranderingen kunnen beoordelen en hoeft niet meer te wachten op het oordeel van de radioloog. Algoritmes kunnen sommige diagnoses nu al beter stellen dan specialisten. ${ }^{1}$ Maar de vervolgstap - op basis van de bevindingen behandelopties met de patiënt bespreken - blijft toch weer mensenwerk. De behandeling heeft immers ook te maken met de wensen en leefomstandigheden van de patiënt. Voor zo'n gesprek zal, door de toepassing van zorgtechnologie, juist meer ruimte ontstaan. De arts krijgt een meer coachende rol, wat ook de kern van het werk als zorgprofessional is."

Toepassing in de praktijk staat of valt ook hier met acceptatie door de professional en de patiënt. De professional zal graag gebruikmaken van zorgtechnologie

\footnotetext{
${ }^{1}$ Dergelijke software valt in een hogere risicoclassificatie volgens de nieuwe Europese wetgeving MDR: "Software intended to provide information which is used to take decisions with diagnosis or therapeutic purposes is classified as class IIa, except if such decisions have an impact that may cause: 1) death or an irreversible deterioration of a person's state of health, in which case it is in class III; or 2) a serious deterioration of a person's state of health or a surgical intervention, in which case it is classified as class IIb.

Software intended to monitor physiological processes is classified as class IIa, except if it is intended for monitoring of vital physiological parameters, where the nature of variations of those parameters is such that it could result in immediate danger to the patient, in which case it is classified as class IIb. All other software is classified as class I." Bron: https://ec.europa.eu/health/ sites/default/files/md_topics-interest/docs/md_mdcg_2019_ 11_guidance_en.pdf.
}

\section{De Diabetes Voetencheck app}

In april 2020, lanceerde RondOm Podotherapeuten een eerste versie van de 'Diabetes Voetencheck app'. De applicatie is ontwikkeld en getest tijdens de COVID-19 lockdown in Nederland, toen de podotherapeut de patiënt alleen op afstand of voor medische urgentie mocht zien. Door het gebruik van de app werden tijdens de eerste periode 186 van de 483 deelnemende patiënten opgeroepen voor een vervolgonderzoek in de praktijk. Daarvan bleken 17 personen wonden te hebben die tot ernstige gevolgen voor de gezondheid hadden kunnen leiden.

\section{Uitdagingen}

Veel uitdagingen blijven echter open, zoals het (opnieuw) bij de praktijk betrekken van mensen met diabetes type 2 die de app gebruiken. Of het leren begrijpen hoe de therapietrouw en het zelfzorggedrag bij deze populatie werkt. Ook het vergroten van het aantal professionals dat de app inzet, is een belangrijk punt. Technische uitdagingen zijn onder meer de matige kwaliteit van de door de patiënt gemaakte foto's en het handmatig beoordelen van de foto door de podotherapeut, wat arbeidsintensief is. Daarnaast liggen er echter ook kansen voor nieuwe functionaliteiten.

\section{Samenwerkende partijen}

Inmiddels is er een subsidie toegekend om de app verder te ontwikkelen, onder de projectnaam Technology support for Diabetes. Development of an application for monitoring of diabetic feet. In dit project worden de hiervoor vermelde uitdagingen opgepakt.

De vier kernpartijen in het project zijn de Fontys Paramedische Hogeschool, RondOm Podotherapeuten, de Technische Universiteit Eindhoven en softwareontwikkelaar Stofloos. Andere betrokken partijen zijn: de NVvP, de Nederlandse Diabetes Federatie, het Diabetes Fonds, Diabetesvereniging Nederland, Zilveren Kruis/Achmea, CZ, en internationaal de FIP-IFP (Fédération Internationale des podologues - International Federation of Podiatrists) en de UNFM (Université Numérique Francophone Mondiale).

die het eigen werk verbetert en het werkproces niet te veel verandert, stelt Wouters. "Maar als het werkproces er wel mee verandert - verschuift naar een andere zorgprofessional bijvoorbeeld, of naar de patiënt - is de acceptatie niet zo vanzelfsprekend. Ook als technologie de intrinsieke waarde van je vak als zorgprofessional dreigt te veranderen, wordt het lastig. Zeker als die verandering financiële gevolgen heeft. Dan gaat het ook om beroepsbelangen en om idealen. Tijdens mij opleiding tot arts bestond het begrip zelfregie nog 


\section{Digitale zorg}

De prestatiebeschrijvingen van de NZa zijn functioneel omschreven. Dit betekent dat de zorg zelf wordt omschreven, maar dat niet wordt voorgeschreven wie de zorg levert, of waar de zorg moet worden geleverd. Dit biedt zorgaanbieders en zorgverzekeraars ruimte om eigen keuzes te maken over de inzet van vormen van digitale zorg. Het staat zorgaanbieders binnen de bestaande prestaties vrij om hun zorgproces te veranderen door bijvoorbeeld face to face contact gedeeltelijk te vervangen door digitale zorg op afstand, of om digitale zorg als aanvulling op de behandeling aan te bieden. Dit is mogelijk zonder dat de bestaande prestaties gewijzigd moeten worden.

niet eens. $\mathrm{Nu}$ is het relevant en je moet willen meegaan in de idealen van de tijd."

Voor acceptatie door patiënten geldt min of meer hetzelfde als voor professionals, stelt Wouters.

\section{Niet invullen voor de patiënt}

Communicatie met de patiënt over de doelstellingen van de digitale zorg en over diens mogelijkheden om bij deze manier van zorg een actieve rol te spelen, is essentieel, maar niet altijd even eenvoudig. "Een patiënt zal immers niet altijd snel willen toegeven dat hij niet goed is met computers", verduidelijkt ze. "Goed doorvragen is dus belangrijk. Verder moet de professional voorkomen dat hij voor de patiënt gaat invullen, en bijvoorbeeld zegt 'dat kan de patiënt helemaal niet'. Patiënten kunnen vaak meer dan behandelaars denken, en ze kunnen dingen leren. Ze gebruiken ook al lang technologie bij het doen van bankzaken of om op internet informatie over hun ziekte op te zoeken. Beslis niet voor de patiënt. Dat gebeurt helaas nog wel eens. We hebben dit in ons onderzoek meegemaakt met patiënten met niet-aangeboren hersenletsel. De behandelaars dachten dat die moeite zouden hebben met monitoring op afstand. Maar de patiënten wilden dit juist heel graag, omdat dit hen meer vrijheid en eigen regie zou geven. De inzet van zorgtechnologie vraagt dus echt om een subtiel samenspel, waarbij de arts fundamentele vragen moet stellen aan de pa- tiënt én aan zichzelf. Ook over privacy natuurlijk. Het zou niet goed zijn als zorgverzekeraars patiënten op basis van data bepaalde zorg gaan ontzeggen, of als patiënten een lagere premie krijgen als ze niet roken en drinken. Het zou zeker niet goed zijn als patiënten zich laten betalen voor het beschikbaar stellen van hun medische gegevens voor onderzoek. Voor mij zit dat bijna op dezelfde schaal als organen verkopen. Ik ben er op ethische gronden heel erg op tegen."

\section{Podotherapie digitaal}

Hoewel sommige podotherapeuten al zeker online actief zijn, doen velen van hen nog niet zoveel op dit gebied, stelt Wouters. "Een deel van het werk zal ook niet gemakkelijk online kunnen, maar online consulten en tussentijdse online controles zijn wel mogelijk. Interessant is ook vierogenbeleid: op afstand meekijken met Smart Glasses (fig. 2) of een andere soortgelijke oplossing. Denk ook aan meekijken naar een voetwond, of - iets heel anders - naar de mogelijkheden en beperkingen van de woonomgeving van de patiënt. Al staan podotherapeuten niet vooraan in de online ontwikkelingen (maar zie het kader 'Diabetes Voetencheck app' [red.]), ze kunnen nu al wel gaan inventariseren welke patiënten zij tijdens de coronapandemie niet bereikt hebben, en welke patiënten heel vaak naar de praktijk komen voor consulten die ook online zouden kunnen plaatsvinden. Natuurlijk moet de financiering voor online consulten dan ook passend geregeld zijn (zie het kader 'Digitale zorg'). Nog een andere digitale oplossing is werken met een digitale agenda waarin patiënten zelf een afspraak kunnen inplannen."

De conclusie van Wouters' verhaal is dus dat ook voor podotherapeuten, net als voor alle andere (para)medische beroepsgroepen, de digitale zorg mogelijkheden biedt, en dat het interessant is om die mogelijkheden te verkennen. Terecht stelt Wouters dat niet alle zorg in de toekomst digitale zorg zal zijn. Maar een deel van de mogelijkheden die nu met de coronacrisis versneld zijn verkend, zal zeker wel zijn stempel gaan drukken.

Frank van Wijck, journalist 